\title{
Study of Recycling of Waste High Impact Polystyrene (PS-HI) and Polystyrene with Flame Retardant Additives (PS-FR) Co-Polymers
}

\author{
Lejalem Haile* \\ Ethiopian institute of Textile and Fashion Technology (EiTEX), Bahir Dar University, Ethiopia
}

*Corresponding author: Lejalem Haile, Ethiopian institute of Textile and Fashion

Technology (EiTEX), Bahir Dar University, Ethiopia.

Received Date: November 25, 2020

Published Date: January 15, 2021

\begin{abstract}
Now a day there are huge amount of solid wastes in the world and are taken as a big challenge to the environment. Because of their environmental impact, the highest attention has been given for recycling of plastics in both consumer products as well as engineering plastics. The objective of this work is to study the recyclability of waste polystyrene co-polymers namely, PS-HI and PS- FR and their application in industrial sector. Material collection, cleaning, sorting, size reduction and granule and product characterizations are sequential activities done during study period. Basically, three characterizations namely chemical characterization (FTIR and EDX), Thermal (TGA, DSC and Cone calorimeter) and mechanical characterization (Tensile stress, Tensile modules and Elongation at break) of high impact polystyrene (PS-HI) and polystyrene with flame retardant additive (PF-FR) was carried out. Finally, after testing Plastic processing (melt flow and Extrusion) and mechanical characterization (tensile strength and modulus), PS-HI sample shows better properties in all aspects and it is taken as a best sample for 3D printing application.
\end{abstract}

Keywords: Waste; Recycling; Characterization; Properties

\section{Introduction}

Polystyrene is a thermoplastic aromatic polymer having linear structure and is a glassy solid bellow its glass transition temperature but tends to change in to soft when the temperature reaches about $100{ }^{\circ} \mathrm{C}$. It was invented by German apothecary Eduard Simon in 1939 (Figure 1).

Because of its good mold ability, polystyrene has huge Varieties of applications including production of Fast food containers, Trays, Egg cartons, disposal drinking cups, Covers and flexures, Cosmetic containers, CD cases, Toys, House wares, Plastic cups and thermal insulation for construction market and similar products (Figure 2).

In the last many years, the highest attention has been given on recycling of plastics in both consumer products as well as engineering plastics. To be recyclable, a plastic material has to exist in PIC (Plastic Identification Code) triangle and here number 6 is given for polystyrene material confirming that the polymer is recyclable even if there are difficulties in controlling processing parameters and getting enough waste materials for recycling [2].

During synthesis of polystyrene, different types of additives were added for improving different properties of a product. Here impact modifier additives were added on polystyrene material to improve mechanical properties of a product through absorption of loads applied on it.

In this paper, the effect of impact modifier additives on recycling of polystyrene materials was studied by taking PS-WI (Polystyrene without impact modifier additives) and PS-HI (Polystyrene with impact modifier additives). 


\section{Materials and Methods}

\section{Material collection and size reduction}

Initially, Scraps of polystyrene products were collected from WEEE (Wastes from Electronics and Electronic Equipment) specifically from Computer Hardware, Printer and Telephone handset. Once materials are collected, sorting were done manually by looking trademarks stamped on the scrap surface and approval of those samples without trademarks were done by conducting FTIR analysis (Figure 3)

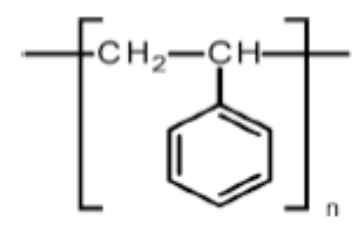

Figure 1: Chemical structure of poly-styrene polymer

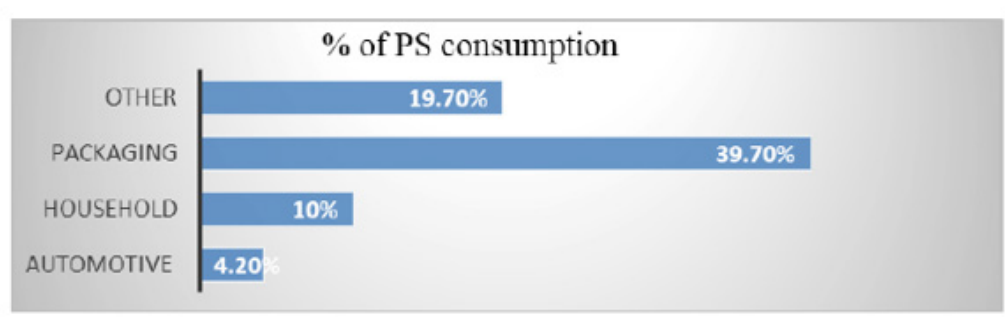

Figure 2: Application of polystyrene in different sectors according to European plastics converter demand in 2016 [1]
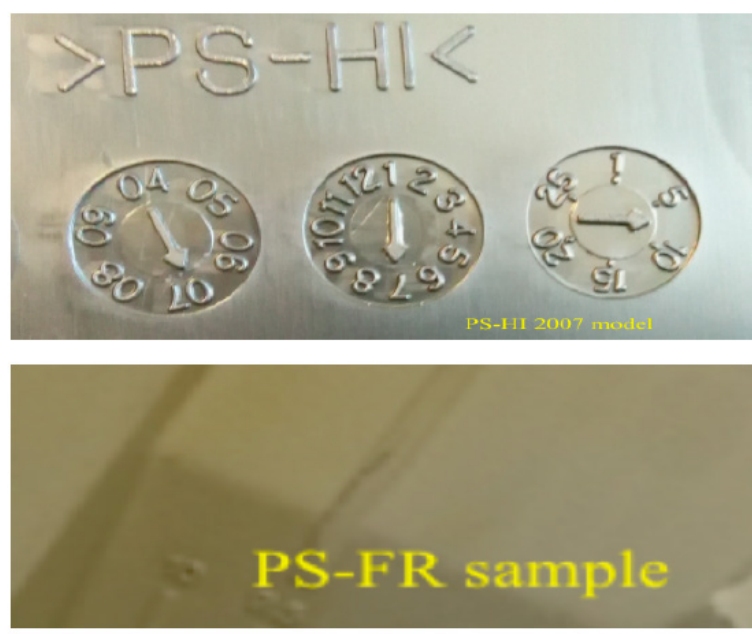

Figure 3: High impact Polystyrene and polystyrene with flame retardant additives.

Since collected materials are contaminated with dusts, oil, grease and other environmental impurities, cleaning was done by using water and 250-300g detergent and finally, the sample was dried using oven and grinded approximately $7-10 \mathrm{~mm}$ size granule powder using size reduction machine (Figure 4).

\section{Fourier transforms infrared spectroscopy (FTIR) analysis}

The chemical structure of sample was analyzed by a Spectrum Perkin Elmer ATR-FTIR covered by diamond reflection accessory for attenuated total reflectance. This analysis was done for identification of samples by looking vibration of their chemical compound and is done by directing infrared ray towards the sample from which some of them are absorbed and the rest are passed (transmitted). The scan was done between $4000 \mathrm{~cm}-1$ and $600 \mathrm{~cm}-1$ averaged for each spectrum at intervals of $1 \mathrm{~cm}-1$ with a resolution of $4 \mathrm{~cm}-1$.

\section{EDX (Energy Dispersive X-ray) analysis}

Energy Dispersive X-ray Spectroscopy (EDX) analysis was done by SEM Jeol IT300 instrument for elemental analysis of samples. The test was done to detect the availability of toxic and environmentally hazardous elements added within additives. 


\section{Thermo gravimetric analysis (TGA)}

Thermal degradation of samples was analyzed by a Q5000 IR thermo gravimetric analyzer (TA Instruments-Waters LLC, New Castle, DE, USA) by taking a weight of $10 \mathrm{mg}$ in an air flow of $15 \mathrm{ml} /$ min from room temperature up to $700{ }^{\circ} \mathrm{C}$ at the rate of $10{ }^{\circ} \mathrm{C} /$ min. The onset temperature of degradation was evaluated from intersection of two tangent lines and the maximum temperature corresponds to maximum of the first derivative of weight loss.

\section{Differential scanning calorimeter (DSC) analysis}

Differential scanning calorimeter (DSC) tests were performed by a Mettler DSC 30 calorimeter (Swiss Mettler Toledo) on samples with a mass of about $10 \mathrm{mg}$ under a nitrogen flow of $100 \mathrm{~mL} / \mathrm{min}$. Heating and cooling cycle of both PS-FR and PS-HI samples was performed in between $0{ }^{\circ} \mathrm{C}$ and $150{ }^{\circ} \mathrm{C}$ with heating and cooling rate of $10{ }^{\circ} \mathrm{C} / \mathrm{min}$ and the sample were cooled to $0{ }^{\circ} \mathrm{C}$. during cooling cycle. Finally, Glass transition temperature (Tg) of samples was measured at the inflection point of the thermos-grams.

\section{Cone calorimeter analysis}

Cone calorimeter is fire testing instrument in which analysis were done based on the consumption of oxygen during combustion process. Here fire behavior of the sample was carried out and analysis was done by radiation of sample surface in different heat fluxes. The sample ignites and burns when excess air is supplied. Finally results of heat release rate (HRR), total heat release rate (THRR), mass loss, amount of smoke, time to ignition (TTI) and other parameters occurring due to burning are evaluated.

\section{Melt flow index}

The melt flow analysis of granule powder was carried out according to ASTM D1238-A standard through a Kayeness Co. model 4003DE capillary rheometer (Morgantown, PA, USA) (with barrel length $162 \mathrm{~mm}$, barrel diameter $9.55 \mathrm{~mm}$, die length $8.0 \mathrm{~mm}$ and die diameter of $2.096 \mathrm{~mm}$ ). About $3-5 \mathrm{~g}$ of each samples of polystyrene was tested at different temperature and load. The result was reported by taking the average values of at least 5 replicates with corresponding standard deviation.

\section{Compression molding}

Compression molding of granule samples were done after removing moisture from the sample through heating and are hot pressed in a Carver Laboratory press at a temperature of 210$220^{\circ} \mathrm{C}$ under the applied load of 10 ton for $15 \mathrm{~min}$ and a cooling rate of $30{ }^{\circ} \mathrm{C} / \mathrm{min}$ to obtain square Plates with dimensions $100 \mathrm{~mm} * 100 \mathrm{~mm}^{*} 1 \mathrm{~mm}$ for mechanical characterization and $120 \mathrm{~mm} * 120 \mathrm{~mm} * 4 \mathrm{~mm}$ for cone calorimeter analysis. Compression molded samples are reported on the result section of the work.

\section{Extrusion (Filament production)}

Powder granule samples were used to feed a Thermo- Hake PTW16 intermeshing co-rotating twin screw extruder having a screw diameter of $16 \mathrm{~mm}$, and die diameter of $3 \mathrm{~mm}$. In processing of both PS-HI and PS-FR, the processing temperature gradually increases from $130{ }^{\circ} \mathrm{C}$ (zone 1), to $200{ }^{\circ} \mathrm{C}$ (zone 2 and zone 3), to $205{ }^{\circ} \mathrm{C}$ (zones 4 ) to $210{ }^{\circ} \mathrm{C}$ (zone 5 - rod die) and the rotational speed of screw and product collection rate were regulated to get a final diameter of the extruded filament of $1.75 \pm 0.10 \mathrm{~mm}$.

\section{D Printing}

$3 \mathrm{D}$ printing of samples was done at $250^{\circ} \mathrm{C}$ by using SHAREBOT Next generation 3D printer machine for producing dumbbell shape specimen to analyze tensile strength and modulus of PS- HI samples.

\section{Tensile test:}

Uniaxial tensile test of samples was done using Instron 5969 electromechanical testing machine consisting of $50 \mathrm{kN}$ load cell. During testing strength at break $(\sigma b)$, deformation at break( $(\varepsilon b)$ and young's modulus(E) of samples were evaluated at extension speed of $0.25 \mathrm{~mm} / \mathrm{min}$ taking an average value of three replicates. During analysis three types of samples namely, compression molded samples of ISO 527 type 1BA dumbbell, extruded filaments and 3D printed specimens were analyzed. According to ISO 527 standard, the elastic modulus of compression molded samples was determined taking the extension values in between $0.05 \%$ and $0.25 \%$.

\section{Result and Discussion}

\section{FTIR analysis}

FTIR (Fourier Transmittance Infrared spectroscopy) is a technique used to identify materials by looking vibration of their chemical compounds. This is done by directing infrared ray towards the sample and some of them are absorbed and others passed (transmitted). This transmission and absorption phenomena are represented by means of spectrum and are responsible for acting as a fingerprint of a sample [4] (Figure 5).

FTIR results for high impact polystyrene and polystyrene flame-retardant samples and their corresponding vibrational peaks are summarized in the following Table 1.

Here 3060 - $3025 \mathrm{~cm}-1$ corresponds to $\mathrm{C}-\mathrm{H}$ aromatic stretch whereas peaks of 2921- $2850 \mathrm{~cm}-1$ indicates symmetric and asymmetric stretch of $\mathrm{CH} 2$. Peaks of $1743 \mathrm{~cm}-1$ indicates the existence of aromatic ring mono-substitution and peaks of 14511493 indicates deformation of $\mathrm{CH} 2+\mathrm{C}=\mathrm{C}$ of aromatic ring. And finally, a peak of 748-695 cm-1 indicates the existence of monosubstituted benzene ring and this can be taken as a reasonable evidence for the sample to be polystyrene.

\section{EDX analysis}

Energy Dispersive X-ray Spectroscopy (EDX) is analytical technique used for elemental analysis of samples and is done by looking the interaction between a source of X-ray excitation, and a sample. The technique is based on the fundamental principle that 
each element has a unique atomic structure allowing X-rays that are characteristic of an element's atomic structure to be identified uniquely from one another. During analysis approximately $20 \mathrm{mg}$ polystyrene sample was taken and analyzed to define the chemical composition of polymeric material and the following results were obtained after analysis (Figure 6 \& Table 2).

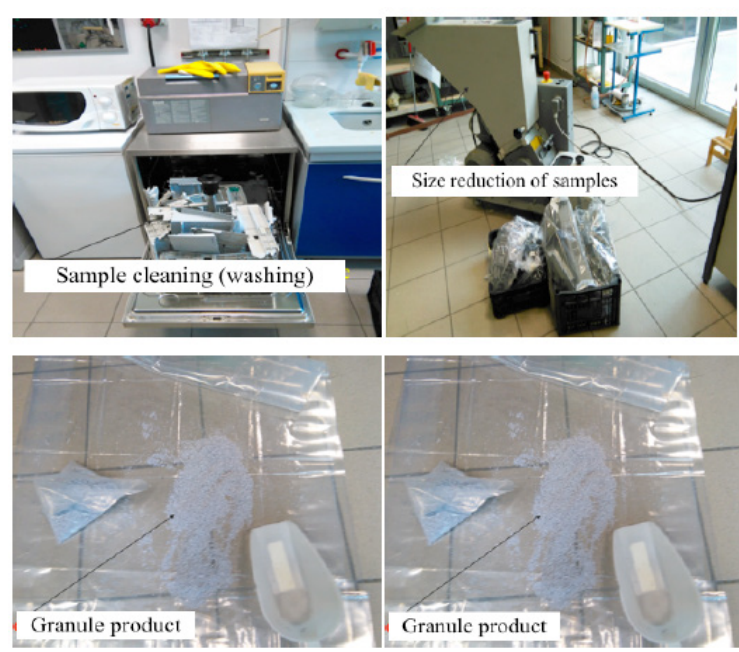

Figure 4: Cleaning, size reduction process of styrene based polymeric materials respectively.

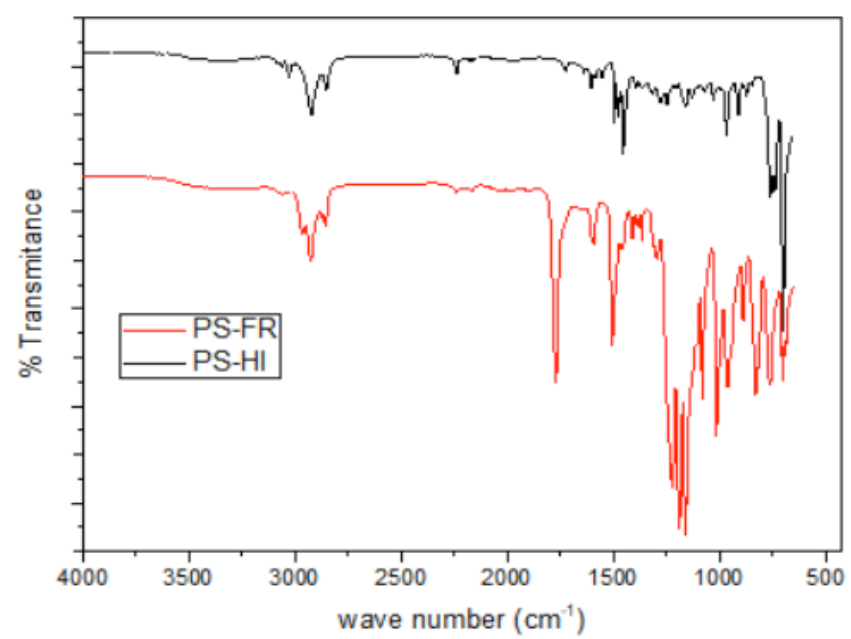

Figure 5: FTIR spectrum of both polystyrene high impact and polystyrene flame-retardant samples.
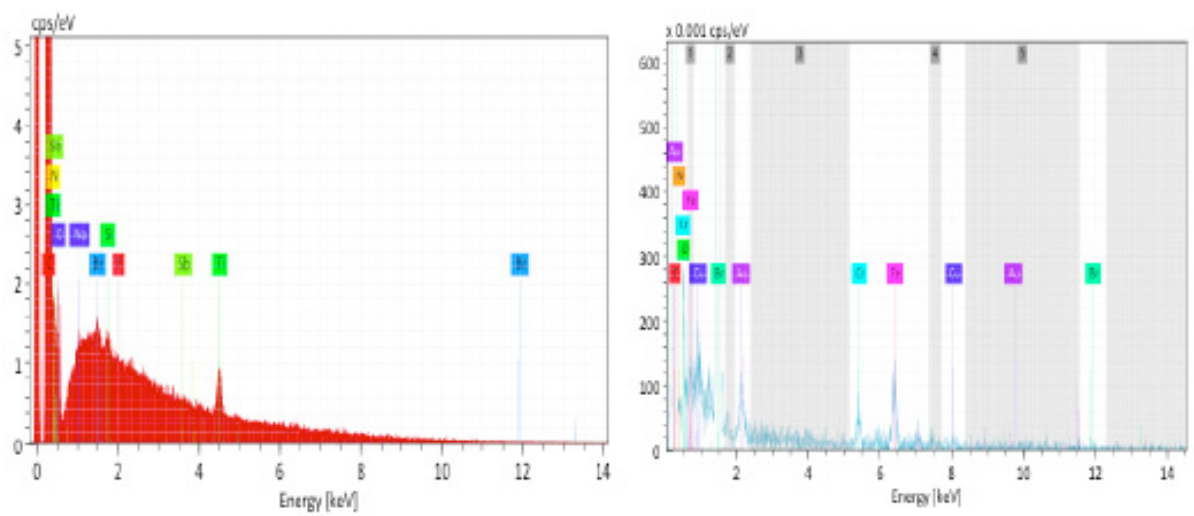

Figure 6: EDX result of both polystyrene high impact and polystyrene flame retardants respectively. 
Table 1: FTIR vibrational peaks of the two copolymers.

\begin{tabular}{|c|c|}
\hline PS-HI peaks $\left(\mathrm{cm}^{-1}\right)$ & PS-FR peaks $\left(\mathrm{cm}^{-1}\right)$ \\
\hline 3082 & - \\
\hline 3060 & - \\
\hline 2921 & 2921 \\
\hline 2851 & 2849 \\
\hline 1942 & 1954 \\
\hline 1743 & 1734 \\
\hline 1601 & 1601 \\
\hline 1493 & 1493 \\
\hline 1451 & 1452 \\
\hline 1180 & 1181 \\
\hline 1154 & 1154 \\
\hline 1068 & 1068 \\
\hline 1028 & 1028 \\
\hline 965 & 965 \\
\hline 906 & 906 \\
\hline 841 & 842 \\
\hline 746 & 748 \\
\hline 691 & 695 \\
\hline
\end{tabular}

Table 2: Elemental analysis results of polystyrene samples.

\begin{tabular}{|c|c|c|c|c|c|c|c|c|c|c|}
\hline Element (\%) & C & $\mathbf{N}$ & $\mathbf{0}$ & $\mathbf{T i}$ & $\mathrm{Br}$ & $\mathbf{S i}$ & $\mathrm{Na}$ & $\mathrm{Cr}$ & $\mathbf{F e}$ & $\mathrm{Cu}$ \\
\hline PS-HI & 92.66 & 5.23 & 1.91 & 0.14 & 0.01 & 0.02 & 0.02 & - & - & - \\
\hline PS-FR & 87.14 & 5.79 & 6.31 & - & 0.02 & - & - & 0.22 & 0.47 & 0.04 \\
\hline
\end{tabular}

As indicated from table 2, trace amount of heavy metals and toxic contaminant elements are obtained after analysis. But according to European directive [5], the threshold value for toxic elements particularly $\mathrm{Cd}, \mathrm{Br}, \mathrm{Cr}$ and $\mathrm{Hg}$ must be $0.1 \%$. In addition, as literatures [6-8] indicates that the concentration of metals and toxic contaminant elements are below the minimum level, the existence of such trace toxic elements in the samples does not taken as a big problem for recycling of this materials.

\section{TGA analysis}

Thermo gravimetric Analysis (TGA) measures the weight loss of a sample as a function of temperature or time and is a useful approach to predict the thermal stability of a sample. During analysis of polystyrene, $10 \mathrm{mg}$ sample was taken, and tests were carried out in an air flow of $15 \mathrm{ml} / \mathrm{min}$ from room temperature up to $700{ }^{\circ} \mathrm{C}$ at the rate of $10{ }^{\circ} \mathrm{C} / \mathrm{min}$ and the following thermo-gram results were obtained after analysis (Figure 7).
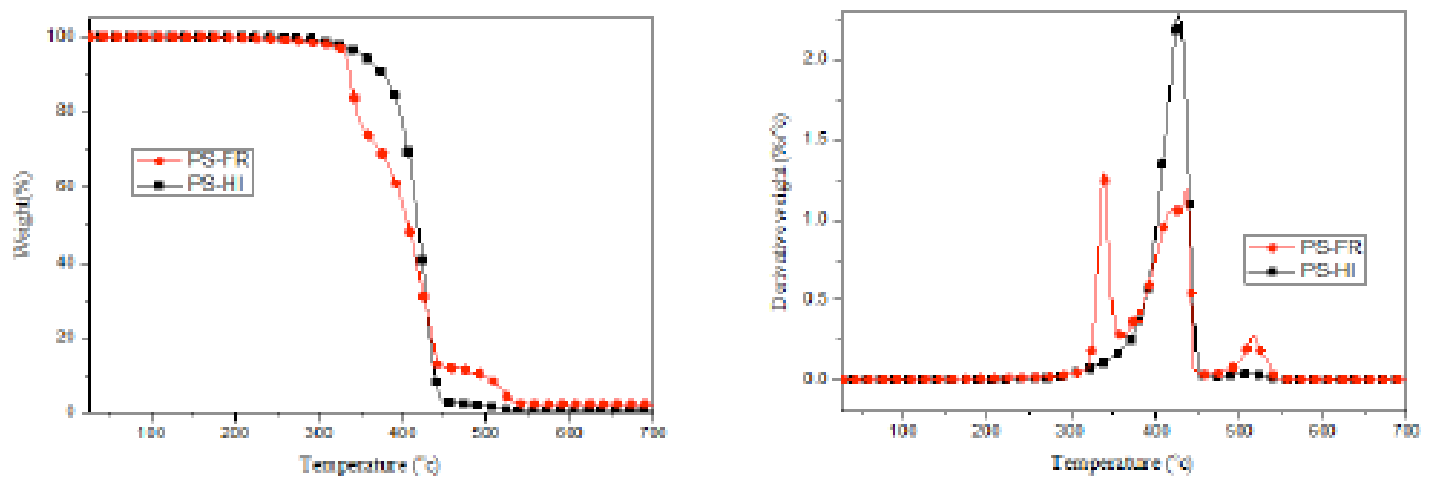

Figure 7: TGA spectrum of both high impact Polystyrene and polystyrene flame-retardant samples. 
From the thermo-gram, the degradation of PS-HI has observed in between $300{ }^{\circ} \mathrm{C}$ to $450{ }^{\circ} \mathrm{C}$. This is the main region in which approximately $95 \%$ of weight loss of the sample takes place. The decomposition process was finished at about $450{ }^{\circ} \mathrm{C}$ but further decomposition was observed from $450{ }^{\circ} \mathrm{C}-535{ }^{\circ} \mathrm{C}$. Since the decomposition of polystyrene is taken in the range $325-425{ }^{\circ} \mathrm{C}$ $[9,10]$, this further decomposition is expected to be most probably the decomposition of additives added during production of polystyrene product.

In analysis of PS-FR samples, three stage pyrolysis has seen on the thermo-gram. The weight loss of the 1st stage takes place from $275-350{ }^{\circ} \mathrm{C}$ which is attributed to degradation of polystyrene and the 2 nd stage of pyrolysis $\left(350-448{ }^{\circ} \mathrm{C}\right)$ is mainly attributed to flame retardant additive. Finally, the third small peak is mainly expected to be peaks related to gases evolved during burning of benzene styrene and alpha methyl styrene mixture.

In comparison to PS-HI the onset temperature for the degradation of PS-FR sample was seen at around $275^{\circ} \mathrm{C}$, but the decomposition temperature of the sample is higher $\left(448^{\circ} \mathrm{C}\right)$, this is due to the fact that brominated polystyrene has high decomposition temperature [11].

Since thermoplastic polymers are working far below their Tg, this slight fluctuation of onset and end temperature of degradation of plastics does not affect applicability of the samples.

\section{DSC analysis}

Differential scanning calorimeter is a technique used for determining the variation in the heat flow given out or taken in by a sample when it undergoes temperature scanning in a controlled atmosphere. With heating or cooling any transformation taking place in a material is accompanied by exchange of heat. DSC enables the temperature of this transformation to be determined and the heat from it to be quantified.

In DSC analysis of polystyrene samples, a mass of about $10 \mathrm{mg}$ sample under a nitrogen flow of $100 \mathrm{ml} / \mathrm{min}$ was used to analyze how material heat capacity changes with temperature and to determine the glass transition temperature of a sample (Figure 8 \& Table 3).

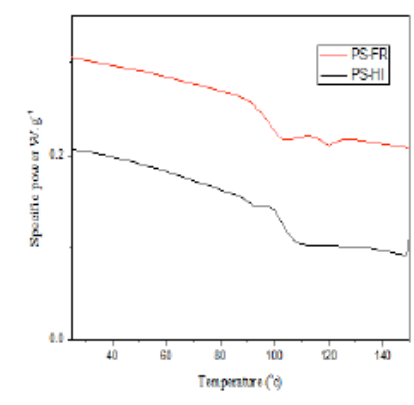

$1^{\text {st }}$ heating

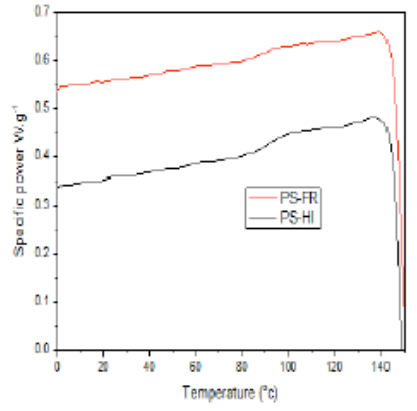

Cooling graph

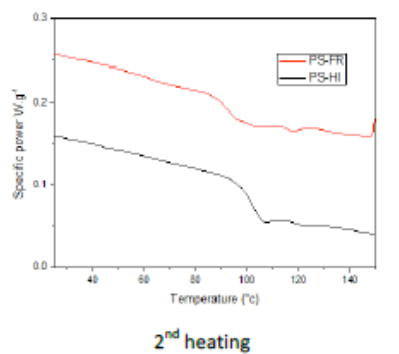

Figure 8: DSC Thermo-gram of both high impact Polystyrene and polystyrene flame-retardant samples.

Table 3: Thermal transition of PS-HI granule powder.

\begin{tabular}{|c|c|c|}
\hline & $\operatorname{Tg}$ of $1^{\text {st }}$ scan heating ${ }^{\circ} \mathrm{C}$ & Tg of $2^{\text {nd }}$ scan heating ${ }^{\circ} \mathrm{C}$ \\
\hline Sample & Tg1 & Tg2 \\
\hline PS-HI & 103 & 102 \\
\hline PS-FR & 92 & 98 \\
\hline
\end{tabular}

Figure 8 shows the DSC thermo-gram referring to first heating, cooling and second heating scans, of PS-HI and PS-FR granule respectively. From the thermos-grams of PS-HI, we can clearly differentiate only one endothermic transition in 1st and 2nd heating which is 102.82 and $102.32{ }^{\circ} \mathrm{C}$ whereas in case of PS-FR sample two consecutive transitions has seen from the thermo-grams of 2 nd 
heating in between $98-120^{\circ} \mathrm{C}$. Here in both cases temperature of $98{ }^{\circ} \mathrm{C}$ and $102{ }^{\circ} \mathrm{C}$ corresponds to the glass transition temperature of polystyrene material in conformity with the literature $[12,13]$. On the other hand, the 2nd transition peak in the 2nd scan heating of PS-FR sample is most probably related to transition of flameretardant additives added during manufacturing of the product.

Here we can conclude that taking other parameters constant, PS-HI has better recyclability in comparison to PS-FR because the higher the glass transition temperature, the higher thermal degradation resistance of material. According to literature [12,13], the glass transition temperature of both samples is in conformity with standard value, the samples are expected to be recyclable.

\section{Cone calorimetric analysis}

Cone calorimeter is fire testing instrument in which analysis were done based on the consumption of oxygen during combustion process. The instrument was used in many research groups for characterization and modeling of fire behavior of materials and is the most power full instrument in fire testing sector [3]. Here the analysis was done by radiation of sample surface in different heat fluxes. The sample ignites and burns when excess air is supplied.

During analysis of polystyrene samples FTT cone calorimeter device with heat flux of $50 \mathrm{KW} / \mathrm{m}^{2}$ and exhaust flow of $24 \mathrm{~L} / \mathrm{s}$ were used, and the test was done on the horizontal position with cone distance of $60 \mathrm{~mm}$.

Thanks to Professor Jose-Marie-Lopez-Questa, PS-HI and PSFR samples were taken to France and cone calorimeter analysis was performed. Here material flammability parameters namely time to ignition (TTI), heat release rate (HRR), peak heat release rate (PHRR), total heat release (THR) and final mass of a sample were analyzed and the following results were obtained after confirmation test of existence of flame retardant additives using cone calorimeter analysis (Tables $4 \& 5$ ).

Table 4: Confirmation result of flame-retardant test of polystyrene samples.

\begin{tabular}{|c|c|c|}
\hline Samples & Fluorescence $\mathbf{X}$ & Cone \\
\hline PS-HI & No RF - Presence of $\mathrm{TiO}_{2}$ & No confirmation of FR \\
\hline PS-FR & Brominated FR with $\mathrm{Sb}_{2} \mathrm{O}_{3}+\mathrm{TiO}_{2}$ & Confirmation of FR \\
\hline
\end{tabular}

Table 5: Evaluation of material flammability parameters of polystyrene samples.

\begin{tabular}{|c|c|c|c|c|c|c|c|c|}
\hline \multicolumn{9}{|c|}{ Test 1} \\
\hline Sample & $\operatorname{TTI}(\mathrm{s})$ & & PHRR(kw/m²) & & $\begin{array}{l}\text { THR at the end of the test } \\
\qquad\left(\mathrm{MJ} / \mathrm{m}^{2}\right)\end{array}$ & & $\begin{array}{c}\text { Final mass } \\
(\%)\end{array}$ & \\
\hline PS-HI & 46 & & 834 & & 271 & & 0 & \\
\hline PS-FR & 54 & & 344 & & 84 & & 5.8 & \\
\hline \multicolumn{9}{|c|}{ Test 2} \\
\hline Sample & & TTI(s) & & $\begin{array}{c}\text { PHRR } \\
\left(\mathrm{kw} / \mathrm{m}^{2}\right)\end{array}$ & & $\begin{array}{l}\text { THR at the end of } \\
\text { the test }\left(\mathrm{MJ} / \mathrm{m}^{2}\right)\end{array}$ & & $\begin{array}{c}\text { Final mass } \\
(\%)\end{array}$ \\
\hline PS-HI & & 45 & & 831 & & 172 & & 0.7 \\
\hline PS-FR & & 47 & & 331 & & 82 & & 5.9 \\
\hline \multicolumn{9}{|c|}{ Average } \\
\hline Sample & TTI(s) & & PHRR $\left(\mathrm{kw} / \mathrm{m}^{2}\right)$ & & $\begin{array}{l}\text { THR at the end of the test } \\
\qquad\left(\mathrm{MJ} / \mathrm{m}^{2}\right)\end{array}$ & & $\begin{array}{c}\text { Final mass } \\
(\%)\end{array}$ & \\
\hline PS-HI & 46 & & 833 & & 172 & & 0.3 & \\
\hline PS-FR & 51 & & 338 & & 83 & & 5.8 & \\
\hline
\end{tabular}

Using cone calorimeter instrument, the existence of brominated FR with $\mathrm{Sb} 2 \mathrm{O} 3+\mathrm{TiO} 2$ was identified in PS-FR sample. Here again we can see that, time to ignition and final mass of the sample was directly related with existence of flame-retardant additives in polystyrene samples.

\section{Melt flow analysis}

Melt flow index (MFI) is the flowing ability of materials in each period and is done to know the applicability of polymers in any standard machine. The melt flow index of any polymeric material is evaluated by calculating the ratio of weight of flow polymers in gram to 10 minutes and the result is commonly known as MFI.
In this study, the melt flow behavior of high impact polystyrene (PS-HI) and polystyrene flame retardant (PS-FR) samples was carried out according to ASTM D1238-A using load of 5kg and temperature of $200{ }^{\circ} \mathrm{C}$. Before start of melt flow test, the sample was dried for $5 \mathrm{hrs}$ in an oven to remove moisture from the sample and $25 \mathrm{mg}$ granule sample was used in each test (Table 6).

The melt flow behavior of PS-HI sample is higher than that of PS-FR. On the other hand, PS-FR shows lower melt flow comparative to PS-HI. This behavior is again expected to be the effect of brominated flame-retardant additive. This is due to the fact that, brominated flame retardants affect the melt flow and decomposition temperature of styrene-based polymers [11]. 
According to ASTM D1238-A, the test result should fail in the range of $0.15-50 \mathrm{~g} / 10 \mathrm{~min}$ to be acceptable. Based on this standard, the result obtained was expected to be acceptable for recycling

\section{Compression molding}

Compression molding of polystyrene samples were done at a temperature of $210{ }^{\circ} \mathrm{C}$ for duration of 15 minutes by using Carver Laboratory press machine. Before pressing, granules of polystyrene were heated at $80{ }^{\circ} \mathrm{C}$ for $5 \mathrm{hrs}$ to remove moisture and loosely bonded surface impurities from the sample and the required amount of sample granule was prepared based on the dimension of the mold. i.e. mold dimension of $120 \mathrm{~mm}^{*} 120 \mathrm{~mm} * 4 \mathrm{~mm}$ for cone calorimeter analysis and $120 \mathrm{~mm} * 120 \mathrm{~mm} * 1 \mathrm{~mm}$ for mechanical characterization was used and the minimum weight of sample granule required for press was obtained by using the following relationship.

but $\mathrm{V}=\mathrm{L}^{*} \mathrm{~W} * \mathrm{~T}$

where $=$ density of granule powder

$\mathrm{m}=$ mass of granule powder

$\mathrm{V}=$ volume of granule powder
$\mathrm{L}=$ length of mold of granule powder

$\mathrm{W}=$ width of mold

$\mathrm{T}=$ thickness of the mold

During press, temperature of $210^{\circ} \mathrm{C}$ with duration of 15 minutes and cooling of 7 miniutes was used to obtain better result for preparing samples used in both cone calorimeter and mechanical characterization (Figures 9\&10).

\section{Extrusion}

Basically, extrusion is the process of heating of thermoplastic polymers beyond its melting temperature and forcing it to flow through the die element. The samples were analyzed by using Thermo- Hake PTW16 intermeshing co-rotating Twin Screw extruder with screw diameter of $16 \mathrm{~mm}$, die diameter of $3 \mathrm{~mm}$ and length to diameter ratio of 25 having five temperature zones. Processing temperature of the sample was adjusted by iterative method until the best quality product was obtained. Here the extrusion temperature starts from $130^{\circ} \mathrm{C}$ (zone 1), to $200^{\circ} \mathrm{C}$ (zone 2 and zone 3), to $205{ }^{\circ} \mathrm{C}$ (zones 4) to $210{ }^{\circ} \mathrm{C}$ (zone $5-$ rod die) (Figures 11-13 \& Table 7).

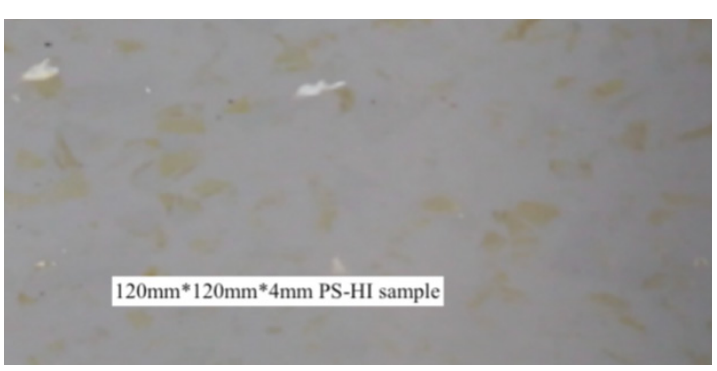

Figure 9: Compression molded HI-PS at $210{ }^{\circ} \mathrm{C}$, for 15 minutes and Cooling time of 7 minutes

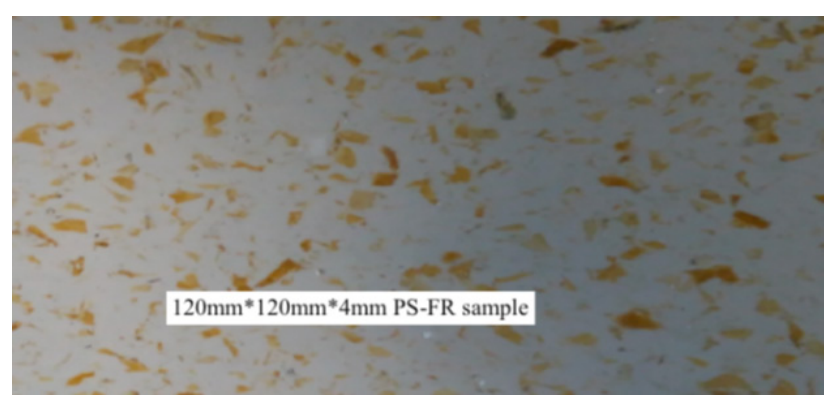

Figure 10: Compression molded sample of PS-FR at $210{ }^{\circ} \mathrm{C}$ for 15 minutes and Cooling time of 7 minutes.

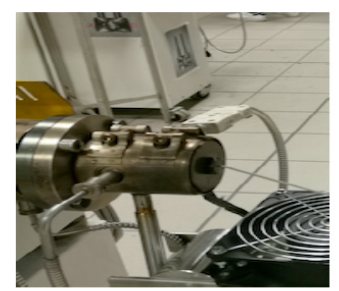

Figure 11: Nozzle of Thermo- Haake PTW16 intermeshing co-rotating twin screw extruder. 
Figure 12: Bundle of extruded PS-HI filament.
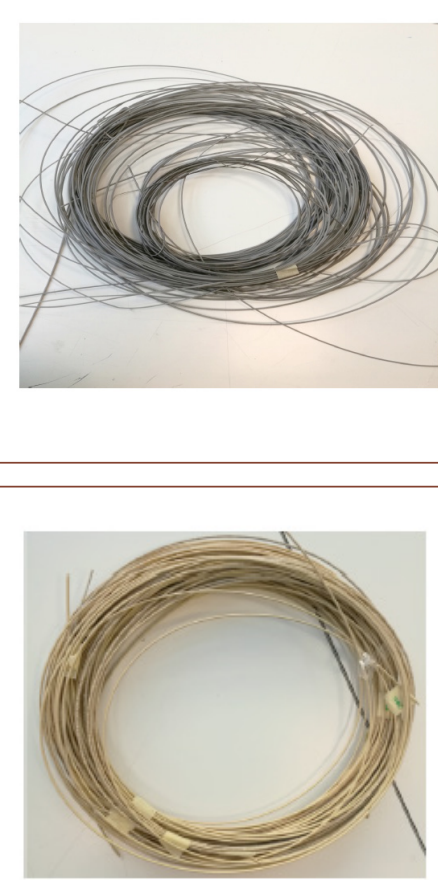

Figure 13: Bundle of extruded PS-FR filament.

Table 6: Melt flow analysis result of polystyrene samples.

\begin{tabular}{|c|c|}
\hline Sample & Melt flow rate $(\mathrm{g} / \mathbf{1 0} \mathbf{~ m i n}), \mathbf{2 0 0}{ }^{\circ} \mathrm{C}, \mathbf{5} \mathbf{k g}$ \\
\hline PS-HI & $5.6 \pm 0.2$ \\
\hline PS-FR & $4.5 \pm 0.1$ \\
\hline
\end{tabular}

Table 7: Temperature setting, linear density, productivity and filament diameter of PS-HI and PSFR samples.

\begin{tabular}{|c|c|c|c|c|c|c|c|c|}
\hline \multirow[b]{2}{*}{ Sample } & \multicolumn{5}{|c|}{ Temperature setting zones $\left({ }^{\circ} \mathrm{C}\right)$} & \multirow{2}{*}{$\begin{array}{c}\text { Linear density } \\
(\mathrm{g} / \mathrm{m})\end{array}$} & \multirow{2}{*}{$\begin{array}{c}\text { Productivity } \\
(\mathrm{g} / \mathrm{min})\end{array}$} & \multirow{2}{*}{$\begin{array}{c}\text { Average diameter } \\
(\mathrm{mm})\end{array}$} \\
\hline & $\mathrm{T} 1$ & $\mathrm{~T} 2$ & T3 & $\mathrm{T} 4$ & $\mathrm{~T} 5$ & & & \\
\hline PS-HI & 130 & 200 & 200 & 205 & 210 & 0.35 & 10.5 & $1.76 \pm 0.02$ \\
\hline PS-FR & 130 & 200 & 200 & 205 & 210 & 0.31 & 8.7 & $1.42 \pm 0.02$ \\
\hline
\end{tabular}

Table 8: Tensile modulus, Tensile strength and extension at break of compression molded polystyrene samples.

\begin{tabular}{|c|c|c|c|}
\hline Sample & E(Mpa) & ob (Mpa) & $\boldsymbol{\varepsilon} \mathbf{b}(\mathbf{m m})$ \\
\hline PS-HI & $2020 \pm 39.21$ & $19 \pm 0.32$ & $0.2 \pm 0.09$ \\
\hline PS-FR & $1692 \pm 98.14$ & $12 \pm 0.41$ & $0.03 \pm 0.01$ \\
\hline
\end{tabular}

As literatures $[13,14]$ suggest that the temperature setting on $\mathrm{T} 1$ is lower and the rest are complementary to the standard. Since the standard diameter of filament for 3D printing is $1.65 \mathrm{~mm}$ up to $1.85 \mathrm{~mm}$, the average diameter of the PS-HI sample is expected to be quite good for $3 \mathrm{~d}$ printing. But PS-FR sample gives crosssectional thin product and is lower than the standard value; we can't use the product (filament) for 3D printing application.

\section{D printing}

Since PS-HI sample shows incredible result for 3D printing, it was done at $250^{\circ} \mathrm{C}$ by using SHAREBOT Next generation 3D printer machine for producing dumbbell shape specimen (Figure 14).

\section{Tensile Modulus of compression molded samples}

ASTM D638 method of tensile testing of plastics is popular method and is done simply by measuring the breaking point and the load required to pull a sample to determine several properties of materials. The data obtained after measurement is helpful to accurately predict the performance of products and their end use. In some cases, the test is known as pull test and it requires "dumbbell" or "dog bone" shape sample specimen which is placed in grips of universal testing machine through which it is subjected to controlled extension until it fails in case of tensile strength test (Figure 15).

In mechanical characterization of polystyrene samples, Uniaxial tensile strength test was performed at room temperature by using Instron 5969 electromechanical testing machine which contains $50 \mathrm{KN}$ load cell. During this analysis, ultimate tensile strength of a sample $(\sigma b)$, deformation at break $(\varepsilon b)$ and elastic 
modulus (E) of the sample were evaluated. For the evaluation, the machine crosshead speed of $0.25 \mathrm{~mm} / \mathrm{min}$ and average values of 5 replicates were taken. In this case compression, molded products ISO 527 type IBA dumbbell shape (thickness $1.22 \mathrm{~mm}$ and length $30 \mathrm{~mm}$ ) were used. Tensile modulus of the sample was evaluated by taking the slope of stress strain curve in between $0.0005 \mathrm{~mm}$ and $0.0025 \mathrm{~mm}$ strain according to ISO 527 type IBA.

\section{Tensile Strength of compression molded samples}

According to the literature values [13], the tensile strength at break of version polystyrene material is $30-60 \mathrm{Mpa}$ and elongation at break is in between $1-4 \%$, and the tensile modulus is 3200 3400 . Here in this analysis, as a recycled material, Tensile strength at break, \% of elongation at break and tensile modulus of PS-HI sample give better result in comparison to PS- FR sample (Figure 16 \& Table 8).

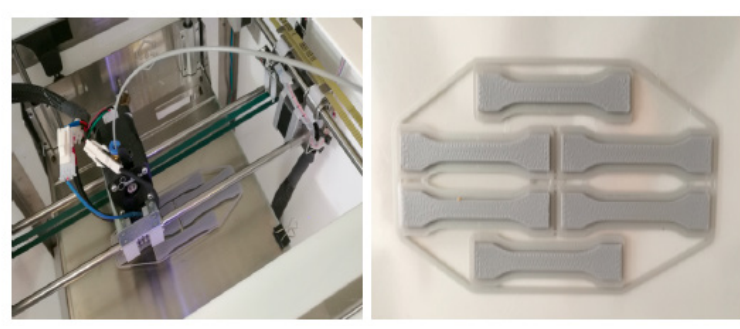

Figure 14: 3D printing of PS-HI sample using SHAREBOT next generation 3D printer machine.

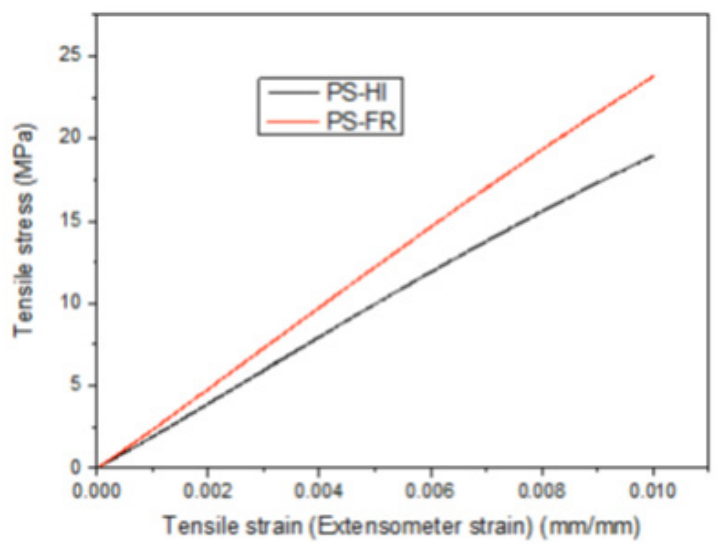

Figure 15: Tensile modulus curve of polystyrene samples.

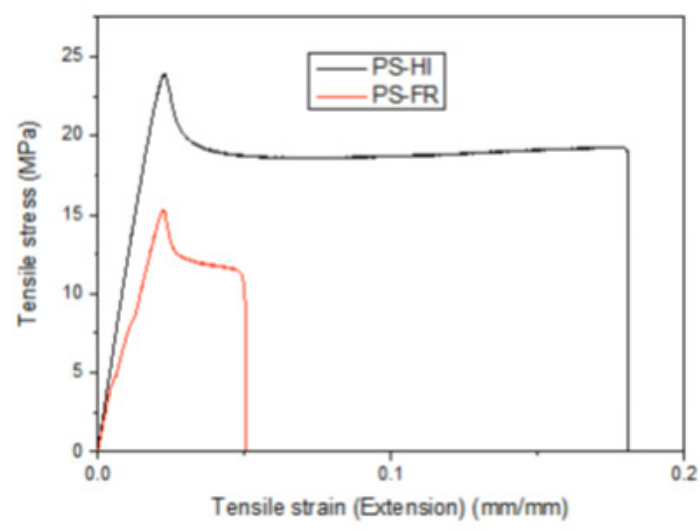

Figure 16: Tensile strength of polystyrene samples.

Particularly percent of elongation at break of PS-HI sample shows incredible result and its tensile modulus is also almost $65 \%$ of that of version material.

\section{Conclusion}

Since the average diameter of PS-HI sample is $1.76 \pm 0.02$, Excellent quality extrusion filament can be obtained by using 
recycled PS-HI copolymer. The chemical, thermal and mechanical characterizations of co-polymers confirmed that, PS-HI shows excellent results in all aspect. Application of recycled PS-HI in 3D printing applications indicates that, the material performed almost as well as standard co-polymer polystyrene sample. Recycling of polystyrene co- polymers is not sophisticated technology with the exception of controlling processing parameters, and it has low environmental impact unless there are brominated additives added during manufacturing of the product.

Future studies will focus on designing a preliminary production plant and Economic feasibility analysis of recycling of polystyrene co-polymers.

\section{Acknowledgement}

None.

\section{Conflict of Interest}

Author declare no conflict of interest.

\section{References}

1. (2020) Analysis of European plastics production, demand and waste data.

2. Acierno S, Carotenuto C, Pecce M (2010) Compressive and Thermal Properties of Recycled EPS Foams. Polymer-Plastic technology and Engineering 49(1): 13-19.

3. (2016) Adsale Ltd, "Medical industry needs spur materials development".
4. Griffiths P, De Haseth J (2007) Fourier transform infrared spectrometry. Hoboken, NJ: Wiley-Inter-science

5. European Parliament and Council (2003) Directive 2002/96/EC of the European Parliament and of the Council on waste electrical andelectronic equipment (WEEE), L37: 24-38.

6. Schlummer M, Gruber L, Mäurer A, Wolz G, van Eldik R (2007) Characterization of polymer fractions from waste electrical and electronic equipment (WEEE) and implications for waste management 67(9): 1866-1876.

7. Wäger PA, Schluep M, Müller E, Gloor R (2010) RoHS substances in mixed plastics from Waste Electrical and Electronic Equipment. Environ Sci Technol 46(2): 628-635.

8. Fink H, Panne U, Theisen M, Niessner R, Probst T, Lin X (2000) Determination of metal additives and bromine in recycled thermoplastics from electronic waste by TXRF analysis. J Anal Chem 368(2-3): 235-239.

9. Kohlman WG (2020) "Mechanical properties of polycarbonatepolysulfone and polycarbonate-polyetherimide".

10. Seleem S, Hopkins M, Olivio J, Schiraldi DA (2017) Thermal decomposition of bio-based polymer aerogels. The Ohio journal of science 117(2): 5060.

11. Leu TS, Wang CS (2004) Synergistic effect of a phosphorus-nitrogen flame retardant on engineering plastics. Journal of Applied Polymer Science 92(1): 410-417.

12. (2020) Glass Transition Temperature (Tg) of plastics.

13. Mark JE (2008) Polymer data handbook Halle/Merseburg Copyright ${ }^{\complement}$ 1999 by Oxford University Press.

14. (2020) Polystyrene and Styrolux ${ }^{\circledast}$. 